\title{
Estudo de uma população relictual de veado-campeiro, Ozotoceros bezoarticus (Linnaeus) (Artiodactyla, Cervidae) no município da Lapa, Paraná, Brasil
}

\author{
Fernanda Góss Braga ${ }^{1}$ \\ Mauro de Moura-Britto ${ }^{1}$ \\ Tereza Cristina Castellano Margarido ${ }^{2}$
}

\begin{abstract}
A relictual population study of pampas deer, Ozotoceros bezoarticus (Linnaeus) (Artiodactyla, Cervidae) at Lapa, Paraná State, Brazil. The pampas deer, Ozotoceros bezoarticus (Linnaeus, 1758) was studied between August 1996 and September 1997 at Fazenda Santa Maria (25⒊' and $25^{\circ} 36^{\prime} \mathrm{S}, 49^{\circ} 46^{\prime}$ and $\left.49^{\circ} 49^{\prime} \mathrm{W}\right)$ at Lapa, Paraná State. During that period we have collected information on feeding habits, group composition, time of the year for birth of youngsters and time for antlers change. The presence of the animal in the area was confirmed by the finding of vestiges and visual occurrences. Animals were observed feeding on young leaves of soya been (Glicine max), oat (Avena sativa), ryegrass (Lolium multiflorum) and barley (Hordeum vulgare). Only one female was observed feeding on dry leaves. A stag was observed feeding on a barley ear. Group's average size was 1.5 individual. Stags/female proportion was 1: 0.96 . Animals displaying velvet coated antlers were observed in June and July which is in accordance with literature about antlers change in a definite period restricted to winter. Only one youngster was observed in September 1996. It is believed that the species survive in the region despite human activities through adaptation of feeding habits with the introduction of agricultural species. This population could disappear in a few years because of the small number of individuals and their isolation.

KEY WORDS. Pampas deer, Ozotoceros bezoarticus, conservation, threatened species, cervidae
\end{abstract}

O veado-campeiro, Ozotoceros bezoarticus (Linnaeus, 1758), também conhecido em algumas regiões como veado-branco, veado-do-rabo-branco, veado-galheiro ou guazu-ti, é a única espécie do gênero Ozotoceros Ameghino, 1891. Sua pelagem varia do marrom avermelhado ao marrom claro (MACHADO 1994) com coloração branca nas regiões perioftálmica, interior das orelhas, inferior do corpo e da cauda, e ao redor do lábio superior. O macho adulto pode atingir cerca de 1,20 a $1,50 \mathrm{~m}$ de comprimento; 0,7 a $0,75 \mathrm{~m}$ de altura e cerca de 30 a $40 \mathrm{~kg}$ (MACHADO 1994). Distingue-se facilmente das outras espécies pelo característico chifre de três pontas, exclusivo dos machos. O chifre cai anualmente e cresce coberto por um tecido chamado de velame, que posteriormente é perdido, deixando o chifre nova-

1) Departamento de Flora e Fauna, Instituto Ambiental do Paraná. Rua Engenheiro Rebouças 1206, 80215-100 Curitiba, Paraná, Brasil. E-mail: bragafg@netpar.com.br ou britto@celepar.gov.br

2) Museu de História Natural de Curitiba. Rua Professor Benedito Conceição 407, 82810-080 Curitiba, Paraná, Brasil. 
mente exposto. Além da presença de galhada, o macho difere da fêmea pelo seu característico odor à alho, que anuncia a proximidade de tropas ou manadas, e que gerou a crença de que seu couro possui propriedades antiofídicas, protegendo de serpentes venenosas quem levasse um pedaço de couro na montaria (CHEBEZ 1994).

Trata-se de uma espécie que habita exclusivamente áreas originalmente formadas por campos e cerrados da América do Sul entre as latitudes $05^{\circ} \mathrm{e} 41^{\circ} \mathrm{S}$ (GoNZALEZ et al. 1998). É um cervídeo social segundo historiadores e naturalistas do século passado, no entanto todos os estudos atuais apresentam marcadas diferenças desta visão histórica (MERINo et al. 1997). Tende a formar grupos que variam de tamanho e composição de acordo com as características e disponibilidade de habitats, de alimento e época do ano (MERINo et al. 1997). A gestação é de aproximadamente sete meses com o nascimento de apenas um filhote; em áreas onde o ambiente permite é capaz de dobrar a sua população em poucos anos (Suzana Gonzales comunicação pessoal). Como ruminantes que são, engolem muito rapidamente uma grande quantidade de alimento e aí então dirigem-se a um lugar seguro para mastigá-lo de forma apropriada (Pough et al. 1993). Alimentam-se basicamente de itens suculentos e leves com alto teor energético e fácil digestão como flores, folhas novas, gomos e arbustos (E.L.A. Monteiro-Filho comunicação pessoal), mas seu comportamento alimentar pode alterar-se de acordo com a variação estrutural do ambiente no qual se encontra (PUTMAN 1988).

Atualmente é uma espécie que merece atenção especial, pois está relacionada no apêndice I da CITES (BERNARDES et al. 1990) e é considerada em perigo no Estado por PARANÁ (1995). A diminuição da população de veados-campeiros deve-se, principalmente, à redução do seu habitat natural devido à ação antrópica, seguido da caça excessiva. A espécie era caçada com fins esportivos, para a alimentação e com o objetivo de retirar as pedras bezoares de seu estômago, às quais se atribuíam propriedades medicinais (DUARTE \& MERINO 1997). A diminuição deve-se também à provável transmissão de doenças por animais domésticos. Segundo SÁENZ (apud CABRERA \& YEPES 1960) a principal causa do quase completo extermínio da espécie na Argentina foi a grande epidemia de febre aftosa que atingiu o país.

Estudos sobre sua distribuição e hábitos têm sido desenvolvidos na região central do Brasil (Tab. I), porém trabalhos com esta espécie no sul do país são inexistentes. Sua ocorrência já foi registrada para o Primeiro e Segundo Planalto Paranaense (Clóvis R.S. Borges comunicação pessoal; Roberto R. Lange comunicação pessoal), mas há muitos anos esta espécie não era visualizada na região.

Este trabalho teve como objetivo confirmar a presença do veado-campeiro na área de estudo e obter informações preliminares sobre a biologia desta espécie.

\section{Área de estudo}

A área de estudo localiza-se no município da Lapa, está compreendida entre as coordenadas geográficas $25^{\circ} 34^{\prime}$ e $25^{\circ} 36^{\prime}$ de latitude sul e $49^{\circ} 46^{\prime}$ e $49^{\circ} 49^{\prime}$ de longitude oeste, distante $92 \mathrm{~km}$ da cidade de Curitiba, capital do Estado.

Esta região sofre a ação de um clima tipo $\mathrm{Cfb}$ - subtropical úmido mesotérmico, de verões frescos com ocorrência de geadas severas e secas, não apresentando estação seca. A média de temperatura dos meses mais quentes é superior a $22^{\circ} \mathrm{C}$, e 


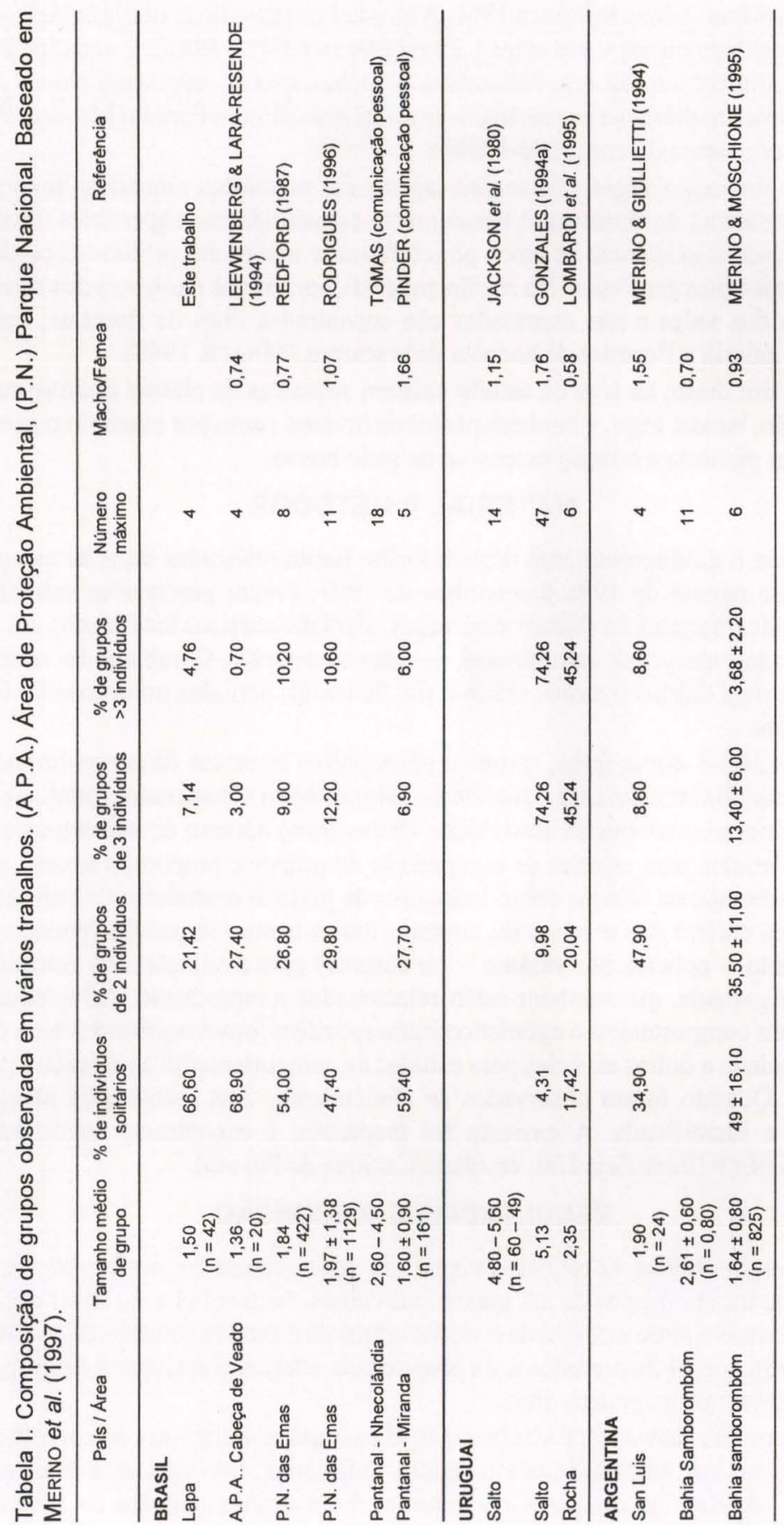


a dos meses mais frios é inferior a $18^{\circ} \mathrm{C}$. A umidade relativa do ar oscila entre $80-85 \%$ e a pluviosidade média varia entre 1.200-1.300 mm (ITCF 1987). É constituída por rochas sedimentares da era Paleozóica e rochas ígneas, apresentando-se como patamar intermediário na sucessão dos grandes planaltos do Paraná (MAACK 1968), com altitude variando entre $800-1000 \mathrm{~m}$.

A formação vegetal da região, apesar das condições climáticas favoráveis para a existência de florestas, é basicamente constituída por superfícies vastas de estepes, dada a existência de solos pouco férteis e não muito profundos conferida pela sua estrutura geológica. Na região em geral, apenas nas nascentes dos ribeirões ao longo dos vales e nas depressões são encontradas ilhas de florestas, capões, florestas galeria e florestas de encosta das escarpas (MAACK 1968).

Além disso, na área de estudo existem sub-areas de plantio onde se cultiva soja, feijão, batata, trigo, e também pastos de inverno como por exemplo o azevém. É também mantida a criação extensiva de gado bovino.

\section{MATERIAL E MÉTODOS}

Para o desenvolvimento deste trabalho foram realizadas fases de campo no período de agosto de 1996 a setembro de 1997. Foram percorridas estradas da propriedade, margens de riachos e córregos, além de carreiros localizados em meio às plantações, através de caminhadas, de carro ou a cavalo. $\mathrm{O}$ trabalho foi realizado em três turnos diários (manhã, início e fim de tarde); períodos noturnos não foram observados.

Vestígios como fezes, rastros e pêlos presos às cercas de arame farpado da propriedade foram coletados. Quando os animais eram visualizados, permaneciam sendo observados até que se afastassem. Dados como número de indivíduos e sexo foram coletados para estudos de composição de grupos e proporção sexual, assim como a presença de filhotes como indicativo de período reprodutivo. O número de pontas dos chifres dos machos foi anotado, assim como seu padrão (presente, em crescimento - coberto por velame - ou ausente) para avaliação dos períodos de trocas de galhada, que também estão relacionados à reprodução. Atividades que indicassem comportamento agonístico intraespecífico foram registradas bem como a proximidade a outras espécies para estudos de comportamento agonístico interespecífico. Quando foram observados se alimentando, uma amostra da planta foi coletada e identificada. A exsicata foi preparada, e encontra-se depositada no Herbário HUCP (Pontifícia Universidade Católica do Paraná).

\section{RESULTADOS E DISCUSSÃO}

Foram obtidos 42 registros visuais de veado-campeiro, deslocando-se solitariamente ou em grupos de até quatro indivíduos (na tabela I é possível observar um comparativo entre este estudo e vários outros de diferentes regiões de ocorrência da espécie), apesar de moradores da propriedade citarem a existência de grupos de até 11 indivíduos há poucos anos.

Segundo NOWAK \& PARADISO (1983) os veados-campeiros vivem solitários, aos pares ou em grupos de três a quatro indivíduos, havendo uma tendência a viverem isolados ou aos pares no inverno, e em grupos maiores na primavera, 
embora os machos mantenham-se preferencialmente solitários durante todo o ano. Os resultados deste trabalho mostram que $58,3 \%$ dos machos estavam solitários quando visualizados, sendo que $28,57 \%$ das visualizações ocorreram no inverno; os maiores grupos foram observados no verão e no outono. Casais de veados foram observados em duas ocasiões; segundo JUNQUEIRA (apud NOGUEIRA-NETO 1973) isto ocorre apenas quando a população da espécie no local está muito reduzida.

Os animais foram visualizados ao longo de todo o dia, porém com maior frequiência nos períodos entre nove e dez horas e 16 e 18 horas, inclusive próximo a áreas de colheita. Em grande parte das observações os animais estavam se alimentando; mostravam-se sempre alertas, alternando atividades de forrageio e vigília. Os ítens identificados foram apenas soja [Glycine max (Linnaeus) Merril.], azevém (Lolium multiflorum Lam.), aveia (Avena sativa Linnaeus) e cevada (Hordeum vulgare Linnaeus), pois estavam em áreas de cultivo. As plantas encontravam-se em estádio inicial de desenvolvimento, embora uma vez tenha sido visualizada uma fêmea se alimentando de folhas secas de soja, apesar da disponibilidade de soja em menor grau de maturação a alguns metros. Apenas um macho foi observado alimentando-se da espiga da cevada, e de uma Fabacea que não pôde ser identificada. MERINo et al. (1997) também descrevem a utilização de L. multiflorum, em escala inferior a $1 \%$ na dieta dos campeiros na Bahia de Samborombóm, Argentina. Outros trabalhos com análise de dieta de veados-campeiros foram desenvolvidos em áreas naturais, não constando portanto estes ítens cultivados em sua dieta.

Os veados observados apresentaram três respostas básicas diferentes mediante aproximação humana. A reação principal foi a de fuga imediata $(53,96 \%)$; o animal levantava prontamente a cabeça e fugia em disparada, geralmente para locais de campo nativo $(88,24 \%)$, caracterizados como áreas de refúgio. Grupos de dois animais que fugiram para lados opostos não voltaram a se reencontrar no período em que continuaram sendo observados. Outra reação foi permanecer imóvel $(20,63 \%)$; esta reação podia ou não ser seguida de fuga, caso a ameaça permanecesse. A terceira reação observada foi abaixar-se em meio à plantação, com o pescoço esticado para frente, paralelo ao solo e orelhas abaixadas $(9,52 \%)$. Com o afastamento do observador, o animal permanecia no local, mas se esse se aproximava, o veado rapidamente levantava e corria em fuga.

A espécie apresentou um comportamento agonístico interespecífico quando estava em atividade de forrageio próxima a grupos de curicacas, Theristicus caudatus Boddaert, 1783. Quando estas aves estavam presentes os veados realizavam postura de vigília com menos freqüência. Os veados utilizavam-se dos sinais de alerta das aves para se proteger. Quando a ave vocalizava sinalizando perigo, os veados imediatamente se colocavam em postura de alerta, com o corpo rígido, o pescoço ereto e orelhas levantadas. Acredita-se que ocorra aí uma relação comensalística, visto que para as aves a presença dos veados parecia ser indiferente; porém, estudos complementares estão sendo realizados. A hipótese das aves se aproveitarem da presença dos veados para se alimentar de insetos que alçassem vôo quando eles se deslocavam foi levantada, porém logo descartada devido a distância mantida entre estas duas espécies. Segundo Flávio H.G. RodRIGUES (comunicação pessoal) caso semelhante parece ocorrer entre veados-campeiros e emas (Rhea americana 
Linnaeus, 1758) no Parque Nacional das Emas. Veados-campeiros não foram vistos próximos aos bovinos e eqüinos da propriedade, embora tenham sido observados lambendo o sal oferecido ao rebanho nos cochos espalhados nas invernadas da propriedade.

Foi observada, em uma ocasião, interação intraespecífica entre machos, onde estes se apoiavam nas patas posteriores e se debatiam com as anteriores. Newton Tércio Netto (comunicação pessoal) cita "empinadas" (rear) onde os animais erguem-se sobre os membros posteriores, mas este comportamento é realizado especialmente por fềmeas e machos após a queda dos chifres. O mesmo autor observou "patadas" (boxing, strike, kicking) onde os animais golpeavam o ar na direção de um outro indivíduo, com movimentos de pedalagem dos membros desferidos durante a empinada. Entrechoques de cabeça, típicos de disputas entre machos, não foram observados.

Descrições da espécie mostram troca de galhadas e nascimento de filhotes em estações bem definidas, variando conforme a localidade. Machos com galhada coberta por velame foram observados nos meses de junho e julho de 1997. O único filhote, de aproximadamente um mês de vida, foi observado, na companhia de uma fêmea e de um macho, no mês de setembro de 1996, havendo, portanto compatibilidade com muitos dados encontrados na literatura de que os picos de nascimento ocorrem entre agosto e outubro (BIANCHINI \& LUNA-PEREZ 1972; JACKSON 1985; JACKSON \& LANGGUTH 1987; REDFORD 1987; LEEUWENBERG \& LARA-RESENDE 1994).

\section{CONCLUSÕES}

A partir dos dados obtidos neste trabalho, supõe-se que a unidade social da espécie na área seja o indivíduo, sendo proporcional o número de machos e fêmeas. Apesar do pequeno número amostral acredita-se que nesta área os machos percam sua galhada em período definido, restrito ao inverno, sugerindo a existência de um ciclo reprodutivo anual. $\mathrm{O}$ fato da espécie ter sido visualizada forrageando apenas em áreas de agricultura não significa que se alimentem apenas dos cultivos, mas é um indicativo da adaptação da espécie a este tipo de ambiente alterado. São também importantes as áreas de campo nativo pois estas são utilizadas para refúgio e descanso, oferecendo segurança a espécie. $\mathrm{O}$ fato de permitirem relativa aproximação humana e de estarem presentes até mesmo em épocas de colheita indica uma certa adaptação à atividade antrópica da região. Esta população não foi estimada mas acredita-se que seja formada por um número reduzido de indivíduos o que, aliado ao isolamento da mesma, faz crer que esta população corre um sério risco de extinguir-se no local em poucos anos.

\section{REFERÊNCIAS BIBLIOGRÁFICAS}

Bernardes, A.T.; A.B.M. Machado \& A.B. Rylands. 1990. Fauna brasileira ameaçada de extinção. Belo Horizonte, Fundação Biodiversitas, 62p.

BIANCHINI, J.J. \& J.C. LuNA-PEREZ. 1972. El comportamiento de Ozotoceros bezoarticus celer Cabrera en cautiverio. Acta Zoologica Lilloana 29: 05-16.

CABRERA, A. \& J. YePes. 1960. Mamiferos sudamericanos. Buenos Aires, Ediar, Vol. 2, 160p.

CHEBEZ, J.C. 1994. Los que se van, especies argentinas em peligro. Buenos Aires, Albatroz, 604p.

Duarte, J.M.B. \& M.L. Merino. 1997. Taxonomia e Evolução, p. 02-08. In: J.M.B. DuarTe. (Ed).

Biologia e Conservação dos Cervídeos Sul-americanos. São Paulo, FUNEP, 238p. 
Gonzalez, S.; J.E. Maldonado; J.A. Leonard; C. Villa; J.M. Barbanti duarte; M. Merino; N. BRUM-ZORRILLA \& R.K. WAYNE. 1998. Conservation genetics of the endangered Pampas deer (Ozotoceros bezoarticus). Molecular Ecology 7: 47-56.

ITCF (Instituto de Terras, Cartografia e Florestas). 1987. Atlas do Estado do Paraná. Curitiba, ITCF, $73 \mathrm{p}$.

JACKSON, J. 1985. Behavioural observations on the argentine Pampas deer (Ozotoceros bezoarticus celer, Cabrera 1943). Ztschr. Saügetierk. 50: 107-116.

JACKSON, J.E. \& A. LANGguth. 1987. Ecology and Status of Pampas Deer in the Argentinian Pampas and Uruguay, p. 402-409. In: C.M. WEMMER (Ed). Biology and Management of Cervidae. Washington, D.C., Smithsonian Inst. Press, 577p.

LEEUWENBERG, F. \& S. LARA RESENDE. 1994. Ecologia de cervídeos na reserva ecológica do IBGE-DF: manejo e densidade de populações. Caderno Geociências, Rio de Janeiro, (11): 89-95.

MAACK, R. 1968. Geografia física do Estado do Paraná. Curitiba, Universidade Federal do Paraná, 350p.

MACHADO, R.B. 1994. Ozotoceros bezoarticus, p. 411-417. In: G.A.B FonSECA (Eds). Livro vermelho dos mamíferos brasileiros ameaçados de extinção. Belo Horizonte, Fundação Biodiversitas, $459 \mathrm{p}$.

Merino, M.L.; S. Gonzales; F. LeeuwenberG; F.H.G. Rodrigues; L. Pinder \& W.M. Tomas. 1997. Veado-campeiro (Ozotoceros bezoarticus), p. 42-58. In: J.M.B. DUARTE (Ed). Biologia e Conservação dos Cervídeos Sul-americanos. São Paulo, FUNEP, 238p.

NowAK, R. \& J. PARADISO. 1983. Walker's Mammals of the World 2. Baltimore, Johns Hopkins University Press, 1362p.

NoguelRA-Neto, P. 1973. A criação de animais indígenas vertebrados - peixes, anfíbios, répteis, aves e mamíferos. Tecnapis, 346p.

PARANÁ. 1995. Lista vermelha de animais ameaçados de extinção no Estado do Paraná. Curitiba, SEMA/GTZ, 177p.

Pough, F.H.; J.B. Heiser \& W.N. McFarland.1993. A vida dos vertebrados. São Paulo, Atheneu, $839 \mathrm{p}$.

PUTMAN, R. 1988. The natural history of Deer. London, Cornell University Press, 191p.

REDFORD, K.H. 1987. The Pampas deer (Ozotoceros bezoarticus) in Central Brasil, p. 410-414. In: C.M. WEMMER (Ed). Biology and Management of Cervidae. Washington, D.C., Smithsonian Inst. Press, $577 \mathrm{p}$.

Recebido em 04.III.1999; aceito em 03.II.2000. 